University of Wollongong

Research Online

Faculty of Engineering and Information

Faculty of Engineering and Information

Sciences - Papers: Part B

Sciences

2019

\title{
Oxidation Behaviour of Steel During hot Rolling by Using TiO2-Containing Water-Based Nanolubricant
}

Hui Wu

University of Wollongong, hwu@uow.edu.au

Chengyang Jiang

University of New South Wales

Jianqiang Zhang

University of New South Wales, j.q.zhang@unsw.edu.au

Shuiquan Huang

University of Queensland

Lianzhou Wang

University of Queensland, I.wang@uq.edu.au

See next page for additional authors

Follow this and additional works at: https://ro.uow.edu.au/eispapers1

Part of the Engineering Commons, and the Science and Technology Studies Commons

Research Online is the open access institutional repository for the University of Wollongong. For further information contact the UOW Library: research-pubs@uow.edu.au 


\title{
Oxidation Behaviour of Steel During hot Rolling by Using TiO2-Containing Water- Based Nanolubricant
}

\author{
Abstract \\ The formation and performance of oxide scale on a low-alloy steel were investigated during hot rolling at \\ 850 and $950^{\circ} \mathrm{C}$ under various lubrication conditions, including benchmarks (dry condition and water) and \\ water-based nanolubricants containing various concentrations of nano-TiO2 from 1.0 to $8.0 \mathrm{wt} \%$. The \\ results showed that the addition of nano-TiO2 particles in the lubricant significantly reduced the thickness \\ of oxide scale and surface oxide roughness. The reduction reached the maximum when the concentration \\ of $\mathrm{TiO} 2 \mathrm{was} 4.0 \mathrm{wt} \%$. Detailed oxide phase characterisation and oxide component fraction determination \\ revealed that hot rolling destroyed the conventional multi-layer oxide scale and promoted magnetite and \\ haematite formation because of easy access of oxygen from the deformed structure. The effect of TiO2 \\ was explained by the decrease in the rolling force, which led to a higher fraction of dense retaining wustite \\ and therefore reduced the extent of further oxidation. Increasing temperature did not change the trend of \\ lubrication effect but raised the rate of steel oxidation in general.

\section{Disciplines \\ Engineering | Science and Technology Studies}

\section{Publication Details} \\ Wu, H., Jiang, C., Zhang, J., Huang, S., Wang, L., Jiao, S., Huang, H. \& Jiang, Z. (2019). Oxidation Behaviour \\ of Steel During hot Rolling by Using TiO2-Containing Water-Based Nanolubricant. Oxidation of Metals, 92 \\ (3-4), 315-335.
}

\section{Authors}

Hui Wu, Chengyang Jiang, Jianqiang Zhang, Shuiquan Huang, Lianzhou Wang, Sihai Jiao, Han Huang, and Zhengyi Jiang 


\section{Oxidation behaviour of steel during hot rolling by using $\mathrm{TiO}_{2}$-containing water-based nanolubricant}

Hui $\mathrm{Wu}^{\mathrm{a}}$, Chengyang Jiang ${ }^{\mathrm{b}}$, Jianqiang Zhang ${ }^{\mathrm{b}^{*}}$, Shuiquan Huang ${ }^{\mathrm{c}}$, Lianzhou Wang ${ }^{\mathrm{d}}$, Sihai Jiao ${ }^{\mathrm{e}}$, Han Huang $^{\mathrm{c}^{*}}$, Zhengyi Jiang ${ }^{\mathrm{a}^{*}}$

${ }^{\text {a }}$ School of Mechanical, Materials, Mechatronic and Biomedical Engineering, University of Wollongong, Wollongong, NSW 2522, Australia

${ }^{\mathrm{b}}$ School of Materials Science and Engineering, The University of New South Wales, Sydney, NSW 2052, Australia

${ }^{c}$ School of Mechanical and Mining Engineering, The University of Queensland, Brisbane, QLD 4072, Australia

${ }^{\mathrm{d}}$ School of Chemical Engineering, The University of Queensland, Brisbane, QLD 4072, Australia

${ }^{\mathrm{e}}$ Baosteel Research Institute (R\&D Centre), Baoshan Iron \& Steel Co., Ltd., Shanghai 200431, China

Abstract: The formation and performance of oxide scale on a low-alloy steel were investigated during hot rolling at 850 and $950{ }^{\circ} \mathrm{C}$ under various lubrication conditions, including benchmarks (dry condition and water) and water-based nanolubricants containing various concentrations of nano- $\mathrm{TiO}_{2}$ from 1.0 to 8.0 $\mathrm{wt} \%$. The results showed that the addition of nano- $\mathrm{TiO}_{2}$ particles in the lubricant significantly reduced the thickness of oxide scale and surface oxide roughness. The reduction reached the maximum when the concentration of $\mathrm{TiO}_{2}$ was $4.0 \mathrm{wt} \%$. Detailed oxide phase characterisation and oxide component fraction determination revealed that hot rolling destroyed the conventional multi-layer oxide scale and promoted magnetite and hematite formation because of easy access of oxygen from the deformed structure. The effect of $\mathrm{TiO}_{2}$ was explained by the decrease in the rolling force, which led to a higher fraction of dense retaining wustite and therefore reduced extent of further oxidation. Increasing temperature did not change the trend of lubrication effect but raised the rate of steel oxidation in general.

Keywords: Nano- $\mathrm{TiO}_{2}$; Water-based nanolubricant; Steel oxidation; Hot rolling *Corresponding authors.

E-mail addresses: j.q.zhang@unsw.edu.au, han.huang@uq.edu.au, jiang@uow.edu.au 


\section{Introduction}

Hot steel rolling is normally carried out in the temperature range from 800 to $1250{ }^{\circ} \mathrm{C}$, during which the oxidation proceeds rapidly [1]. In general, the oxide scale formed on a hot-rolled steel strip is of vital importance in the subsequent industrial processes, including pickling, cold rolling, heat treatment and electrolytic tinning [2]. It is thus essential to remove the oxide scale by use of acid treatment to ensure high quality surface of strip for further processing. The amounts of descaled oxides are greatly associated with the yield of finished products and the consumption of acid, i.e., a thin oxide scale is desired to decrease material loss and usage of the acid solution. In some cases, it is feasible to produce as-hot-rolled steel strip that has pickle-free 'tight oxide scale' formed on the strip surface prior to downstream processing such as stamping in automobile manufacturing [3]. As reported in the previous studies [4, 5], the tight oxide scale can be deformed with steel substrate without cracking, and it may act as a lubricant between the tool and the workpiece. This proposed oxide scale consists of more than $75 \%$ magnetite and residual wustite with a total thickness of less than $15 \mu \mathrm{m}$ [3].

A great deal of research was focused on the effect of oxide scale on the tribological feature during hot metal working [6-10]. For examples, Munther and Lenard [8] investigated the effect of scaling on interfacial friction in hot steel rolling, and they found that a thicker scale resulted in a lower coefficient of friction. Luong and Heijkoop [9] studied the effect of scale on friction in hot metal working. They also concluded that thicker scales led to lower friction values, and the scale thickness appeared to be more important than the scale composition. Utsunomiya et al. [10] put forward that the oxide scale formed on steel surface could be regarded as a lubricant to decrease the friction in hot rolling, and the main mechanism was ascribed to the relative sliding of the scale with respect to the matrix steel.

It has been well-known that the oxide scale formed on mild steel at high temperatures is primarily composed of three layers, namely, a thicker innermost layer of wustite, an intermediate layer of magnetite, and a thin outermost layer of hematite [11]. In essence, temperature significantly affects the fraction of three different oxide phases within the scale. For instance, magnetite phase dominates the scale at temperatures below $650{ }^{\circ} \mathrm{C}$, while wustite prevails at high temperatures $\left(>650{ }^{\circ} \mathrm{C}\right)$ with low fraction of hematite in either case $[12,13]$. Additionally, wustite is thermodynamically unstable at temperatures 
lower than $570{ }^{\circ} \mathrm{C}$, and it is thus decomposed to magnetite and iron according to the iron-oxygen equilibrium phase diagram [14]. Besides, other factors such as substrate grain size [15], cooling rate [16], atmospheric conditions [17], and alloying elements [18] also determine the proportion of the three oxide phases. It has been widely accepted that hematite tends to increase friction and wear due to its high hardness and abrasive behaviour, while magnetite and wustite are more ductile and have a better wear resistance [19]. Therefore, the oxide scale with considerable amounts of magnetite and wustite precipitates is highly required after hot steel rolling.

In recent years, investigations on nanomaterials as additives in lubricant have drawn significant attention due to their excellent tribological performance and lubrication effectiveness [20-23]. In particular, water-based nanolubricants have presented a prevailing trend to substitute conventional oil-in-water emulsions and other oil-based lubricants in hot rolling of steels in consideration of energy saving and environmental protection [24-27]. The effect of lubrication on the formation of oxide scales has been revealed simultaneously. Bao et al. [24] applied water-based nanolubricant containing nano- $\mathrm{SiO}_{2}$ to study its effect on surface qualities of hot rolled steel strip. They found that the thickness of oxide scale was decreased by $46.7 \%$ when $0.3 \mathrm{wt} \% \mathrm{SiO}_{2}$ was added into the base lubricant. Meng et al. [25] chose nano- $\mathrm{TiO}_{2}$ lubricating fluid to investigate its effect on the surface and metallographic structure of hot rolled steel strip. They proposed that the oxide caused by nano- $\mathrm{TiO}_{2}$ fluid had a thinner scale of $20 \mu \mathrm{m}$ than that of $40 \mu \mathrm{m}$ obtained without any lubrication. Our previous studies [26,27] also indicated that the oxide scale thickness produced under dry condition in hot steel rolling could be maximally reduced by 43.8\% under nanolubricant containing $4.0 \mathrm{wt} \% \mathrm{TiO}_{2}$. The effects of using nanolubricant on steel oxidation, however, were only confined to the entire thickness of oxide scale. The detailed formation and composition of oxide scale on steel hot rolling have not been systematically examined.

In the present work, the water-based nanolubricants with varying concentrations of nano- $\mathrm{TiO}_{2}$ were employed to study their lubrication effectiveness on the steel oxidation during hot rolling. The effect of different lubricants on the oxide scale formation was examined by use of quantitative analyses of various oxide phases produced. The correlation between the effect of lubrication and the composition/morphology of oxides was established for understanding the lubrication mechanism in hot steel rolling. 


\section{Experimental details}

\subsection{Materials}

The material used in this study was a low-alloy steel plate with a yield stress of $345 \mathrm{MPa}$. Its chemical compositions are shown in Table 1 . The steel plates were machined to dimensions of 300 (Length) $\times 48$ (Width) $\times 8$ (Thickness) $\mathrm{mm}^{3}$ with tapered edges for an easy roll bite where non-deformed steel oxidation occurred during hot rolling, as schematically shown in Fig. 1. Both sides of the steel plates were ground and polished to generate identical surfaces with a roughness $\left(\mathrm{R}_{\mathrm{a}}\right)$ of around $0.5 \mu \mathrm{m}$. Prior to each hot rolling test, the plate was cleaned with acetone to remove any residuals retained from machining.

Table 1 Chemical compositions of the low-alloy steel Q345 (wt\%).

\begin{tabular}{ccccccccc}
\hline $\mathrm{C}$ & $\mathrm{Si}$ & $\mathrm{Mn}$ & $\mathrm{Mo}$ & $\mathrm{Ni}$ & $\mathrm{Cr}$ & $\mathrm{P}$ & $\mathrm{S}$ & $\mathrm{Nb}+\mathrm{V}+\mathrm{Ti}$ \\
\hline 0.16 & 0.25 & 1.5 & 0.007 & 0.006 & 0.02 & 0.015 & 0.004 & $<0.02$ \\
\hline
\end{tabular}

Water-based nanolubricants containing various concentrations of nano- $\mathrm{TiO}_{2}$ being used in this study consist of $\mathrm{TiO}_{2} \mathrm{NPs}$, polyethyleneimine (PEI), glycerol and balanced water. The nano- $\mathrm{TiO}_{2}$ is $\mathrm{P} 25$, a mixture of $75 \%$ of anatase and $25 \%$ of rutile with the diameter of approximately $20 \mathrm{~nm}$. The synthesis procedure of the nanolubricants can be found elsewhere, exhibiting superior dispersion stability [28, 29]. Steels under dry and water conditions were also tested to compare with the water-based nanolubricants. The compositions of all applied lubricants are listed in Table 2.

Table 2 Chemical compositions of applied lubricants.

\begin{tabular}{cc}
\hline Lubrication type & Description \\
\hline 1 & Dry condition (in air) \\
2 & Water \\
3 & $1.0 \mathrm{wt} \% \mathrm{TiO}_{2}+0.01 \mathrm{wt} \% \mathrm{PEI}+10.0 \mathrm{vol} \%$ glycerol + balance water \\
4 & $2.0 \mathrm{wt} \% \mathrm{TiO}_{2}+0.02 \mathrm{wt} \% \mathrm{PEI}+10.0 \mathrm{vol} \%$ glycerol + balance water \\
5 & $4.0 \mathrm{wt} \% \mathrm{TiO}_{2}+0.04 \mathrm{wt} \% \mathrm{PEI}+10.0 \mathrm{vol} \%$ glycerol + balance water \\
6 & $8.0 \mathrm{wt} \% \mathrm{TiO}_{2}+0.08 \mathrm{wt} \% \mathrm{PEI}+10.0 \mathrm{vol} \%$ glycerol + balance water \\
\hline
\end{tabular}




\subsection{Hot rolling tests}

Hot rolling tests were conducted on a 2-high Hille 100 experimental rolling mill. The work roll has a dimension of $\varnothing 225 \mathrm{~mm} \times 254 \mathrm{~mm}$, and a surface roughness of $1.0 \mu \mathrm{m}$ in $\mathrm{R}_{\mathrm{a}}$. The procedure of hot rolling test is shown in Fig. 2. The steel plates were heated in a high temperature electric resistance furnace at temperatures of 900 and $1000{ }^{\circ} \mathrm{C}$, respectively, for a period of $30 \mathrm{~min}$ within an atmosphere of nitrogen. The hot plates were then rolled at estimated temperatures of 850 and $950{ }^{\circ} \mathrm{C}$, respectively, with a reduction of $30 \%$ and a rolling speed of $0.35 \mathrm{~m} / \mathrm{s}$ under different lubrication conditions mentioned in Table 2. After rolling, the steel strips were immediately transferred into a sealed cooling box inflated with nitrogen. It is noted that the nitrogen was used in both the furnace and the cooling box to restrain the hot steel from being oxidised in air. The extra steel oxidation occurred at the entrance and exit of rolling mill could thus be minimised, respectively, in each instant period (about $1 \mathrm{~s}$ for each period). As stated in the previous studies $[26,27]$, the pure water and water-based lubricants were sprayed onto the pre-cleaned work roll surfaces ahead of each rolling test until a uniform and saturated layer of liquid film was formed. Due to the different wettabilities of lubricants on roll surfaces, the effective amounts of lubricants adhered were inconsistent. All experiments were repeated twice to ensure replicability. Once the rolled strips were cooled down and removed from the sealed box, the top surfaces of the strips were covered with a mixture of epoxy resin and hardener to protect the oxide scale. After $24 \mathrm{~h}$, the resin was coagulated. The protected oxide scale parts were then sectioned along the rolling direction into pieces with dimensions of 20 (L) $\times$ $10(\mathrm{~W}) \times 10(\mathrm{~T}) \mathrm{mm}^{3}$ by the use of a Struers Accutum-50 cutting machine. After that, the cross sections of the pieces were ground and polished, and then cleaned in ethanol using ultrasonic agitation before being dried and stored in a desiccator for further analysis.

\subsection{Characterisation}

The surface topography of oxide scales formed after rolling was characterised using a KEYENCE VK-X100K 3D Laser Scanning Microscope. The optical images of the cross-section of oxide scales were captured to determine the thickness of oxide scales and oxide morphologies.

The oxides formed inside oxide scales were identified by a Raman microscope (Renishaw inVia Raman Microscope, UK). In Raman spectrum measurement, the excitation wavelength of Ar-ion laser was 514 
$\mathrm{nm}$ with a beam spot size of $1.5 \mu \mathrm{m}$. The low laser power employed in the Raman spectroscopy was to avoid wustite oxidation under illumination during the measurement. The measurement was conducted in the Raman shift range from 100 to $1500 \mathrm{~cm}^{-1}$ where all typical peaks for hematite, magnetite and wustite were displayed. The fractions of these oxides were quantified by using the optical microscope images according to the contrast difference distinguished by Photoshop with an image analysis software Image J. The results of oxide fraction were obtained by measuring the average values of more than three different areas in each sample. Some oxide scales were further analysed by using scanning electron microscopy (SEM, Hitachi 3400, Japan).

\section{Results}

\subsection{Surface topographies of oxide scale}

Fig. 3 shows the 3D topographies of oxide scales produced at $850{ }^{\circ} \mathrm{C}$ under dry, $1.0 \mathrm{wt} \% \mathrm{TiO}_{2}, 4.0 \mathrm{wt} \%$ $\mathrm{TiO}_{2}$ and $8.0 \mathrm{wt} \% \mathrm{TiO}_{2}$ lubrication conditions. It can be seen from Fig. 3a that the use of dry condition results in the oxide scales with severe ups and downs over the scale surface. In contrast, the application of nanolubricants is inclined to yield relatively smooth surfaces, and the trend becomes increasingly significant with the increase of nano- $\mathrm{TiO}_{2}$ concentration being used (see Fig. 3b-d). Most importantly, the oxide scale with the smoothest surface is generated by using the nanolubricant containing $4.0 \mathrm{wt} \% \mathrm{TiO}_{2}$, as shown in Fig. 3c. A further increase of nano- $\mathrm{TiO}_{2}$ concentration to $8.0 \mathrm{wt} \%$ seems to have no further improvement on the surface smoothness of oxide scale (see Fig. 3d).

Fig. 4 shows 3D topographies of the oxide scales formed on the rolled steel surface at $950{ }^{\circ} \mathrm{C}$ under the same lubrication conditions as in Fig. 3. It is found that the oxide scales exhibit an overall rise in surface undulations, compared to those formed at $850^{\circ} \mathrm{C}$. The similar phenomenon, however, is that the surfaces can be apparently flattened by means of nanolubricants in comparison to that under dry condition. Additionally, the nanolubricant containing $4.0 \mathrm{wt} \% \mathrm{TiO}_{2}$ leads to the oxide scale with the smoothest surface among all of the rolled surfaces. By referring to the 3D topographies displayed in Figs. 3 and 4, the surface roughness values of oxide scales could be obtained, and the values at both 850 and $950{ }^{\circ} \mathrm{C}$ using all various lubrication methods are shown in Fig. 5. It is concluded that a lower rolling temperature brings forth a relatively smaller surface roughness. It is also found that in addition to the lowest roughness 
obtained at $4.0 \mathrm{wt} \% \mathrm{TiO}_{2}$, the difference in surface roughness at 850 and $950{ }^{\circ} \mathrm{C}$ becomes the least significant at this nano- $\mathrm{TiO}_{2}$ concentration.

\subsection{Thickness of oxide scale}

Fig. 6 shows the optical images of cross-section of oxide scales formed at $850{ }^{\circ} \mathrm{C}$ under some selected lubrication conditions. It can be observed that hot steel rolling without lubrication triggers the thickest oxide scale among all the cases. The extent of thinning the scale proceeds progressively with the increase of nano- $\mathrm{TiO}_{2}$ concentration from 1.0 to $4.0 \mathrm{wt} \%$ in the lubricant, whereas an even higher concentration of $8.0 \mathrm{wt} \% \mathrm{TiO}_{2}$ causes a slightly higher scale thickness instead. Although increasing the rolling temperature

to $950{ }^{\circ} \mathrm{C}$, the oxide scales formed are greatly thickened, as shown in Fig. 7, the variation trend of the scale thickness at $950{ }^{\circ} \mathrm{C}$ is consistent with that obtained at $850{ }^{\circ} \mathrm{C}$. The quantitative comparison of the scale thickness at the two temperatures is shown in Fig. 8. Of specific interest here is that the oxide scale thickness formed under dry condition can be maximally reduced by $81.8 \%$ and $43.4 \%$, respectively, with respect to rolling temperatures of 850 and $950{ }^{\circ} \mathrm{C}$ by use of the nanolubricant containing $4.0 \mathrm{wt} \% \mathrm{TiO}_{2}$. Apart from that, the use of water enables a slightly thinner oxide scale than that obtained under dry condition.

\subsection{Oxide morphology and phase characterisation}

Oxide morphology was further examined by metallographic analysis. Fig. 9a-d show the optical and SEM back scattered electron (BSE) cross-sectional images of non-deformed steels (samples obtained from the tapered edge of the steel, see Fig. 1) at 850 and $950{ }^{\circ} \mathrm{C}$. It is observed that the steel generally consists of three oxide layers, a very thin bright top layer, a rather thick dark grey inner layer in contact with the steel substrate, and a relatively thin grey interlayer in between (see Fig. 9a and c). Beyond that, there are also clear grey particles inside the thick dark grey oxide layer. The formation of these particulate precipitates is confirmed by SEM-BSE images, as shown in Fig. $9 \mathrm{~b}$ and d. In both cases, the whole oxide scale is detached from the steel substrate where there is a thin oxide layer formed on the surface (see Fig. 9b and d). In addition, some pores and cracks are found in the oxide scales.

In order to identify the iron oxides in the scale, Raman spectroscopy was used. According to the Raman spectra shown in Fig. 9e, the top thin layer of the scale (point 1) is hematite $\left(\mathrm{Fe}_{2} \mathrm{O}_{3}\right)$, which remains at 
both temperatures [30]. The thick inner layer (point 3) is confirmed as wustite (FeO), which dominates in the scales. The interlayer (point 2 in Fig. 9a and c) is identified as magnetite $\left(\mathrm{Fe}_{3} \mathrm{O}_{4}\right)$. The homogeneously scattered precipitates (point 2) in the wustite layer are found to be magnetite $\left(\mathrm{Fe}_{3} \mathrm{O}_{4}\right)$. The thin oxide layer at the seam of scale/substrate is confirmed as magnetite $\left(\mathrm{Fe}_{3} \mathrm{O}_{4}\right)$ too. The three different oxide phases can be distinguished directly in metallographic images by their slightly different contrasts.

Fig. 10a-d show the optical cross-sectional images of steels under dry and water conditions at 850 and $950{ }^{\circ} \mathrm{C}$. It can be seen clearly that the oxide scale is deformed severely due to the impact of the rolling force at both temperatures, which leads to a substantially increased number of pores and cracks. The multi-layered structure obtained in non-deformed steel shown in Fig. 9 does not appear in this situation. It seems more hematite (bright phase) and magnetite (grey phase) but almost no wustite (dark grey phase) are formed. Clearly, the phase compositions of the scales obtained under dry and water conditions are different from those in non-deformed steels.

The optical images of the oxide scales formed on the rolled steel along cross sections at 850 and $950{ }^{\circ} \mathrm{C}$ under various nanolubrication conditions are presented in Fig. 11. The trend of the scale thickness is consistent with that shown in Fig. 8. The oxide scale still has certain number of pores and cracks due to the deformation at both temperatures, but the extent is slighter than that under dry and water conditions. Generally, the porosity is inversely proportional to the nano- $\mathrm{TiO}_{2}$ concentration in the lubricant from 1.0 to $4.0 \mathrm{wt} \%$, then increases instead when the concentration reaches $8.0 \mathrm{wt} \%$. In addition, all three oxide phases all exist in the scales formed on steel surfaces under nanolubrication conditions. The sequence of the three oxide scales from the top to the interior is the same with that of the scales formed on the non-deformed steels. However, the thickness and proportions of the three oxide phases change with nano- $\mathrm{TiO}_{2}$ concentration, which will be illustrated in details below. The red dot lines shown in Fig. 11a-h reveal the interface between magnetite and wustite. It can be seen that although the precipitated $\mathrm{Fe}_{3} \mathrm{O}_{4}$ particulates are not scattered homogeneously in the inner wustite layer, the shell-like structure with magnetite layer decorated wustite is observed nearby the pores or cracks (see Fig. 11i). In order to quantitatively investigate the influence of various lubrication conditions on oxide compositions in the oxide scale, the fractions of three iron-oxide phases and porosity produced under 
various lubrication conditions at 850 and $950{ }^{\circ} \mathrm{C}$ were measured. Three optical cross-section images in different locations of each sample were used to acquire the average value and the standard deviation of fractions of three iron-oxide phases and porosity. The results are summarised in Fig. 12. It can be seen that non-deformed oxide scale contains all three iron-oxide phases with clearly highest fraction of wustite. The oxide scale formed under dry and water conditions exhibits very high porosity and no detectable wustite from the image analysis. However, with the application of $\mathrm{TiO}_{2}$-containing water-based nanolubricants, the porosity is reduced and wustite appears. Furthermore, the porosity in the oxide scale is inversely proportional to the increase of nano- $\mathrm{TiO}_{2}$ concentration from 1.0 to $4.0 \mathrm{wt} \%$. In particular, the lubricant containing $4.0 \mathrm{wt} \% \mathrm{TiO}_{2}$ produces the lowest porosity among all the water-based nanolubricants. When the nano- $\mathrm{TiO}_{2}$ concentration continues to increase to $8.0 \mathrm{wt} \%$, the porosity increases slightly. On the other hand, the fraction of wustite displays an opposite trend, increasing with the increase of nano- $\mathrm{TiO}_{2}$ concentration from 1.0 to $4.0 \mathrm{wt} \%$ and then slightly decreasing. Although the fractions of magnetite are dominant among three iron oxides in the hot rolled steels, there is no clear change of this fraction with the variation of the lubricants. It should also be mentioned that the fraction of hematite in general increases in the rolled samples compared with the non-deformed one.

\section{Discussion}

\subsection{Polishing and mending effects of nanolubricant}

Surface roughness analysis results (Figs. 3 and 4) revealed a significant effect of lubricant on hot rolled steel surface quality. The best surface quality with the lowest surface roughness was achieved when using $4.0 \mathrm{wt}^{\%} \mathrm{TiO}_{2}$ lubricant. It is acknowledged widely that the nanoparticles (NPs) suspended in base lubricant are committed to rolling effect, mending effect, polishing effect and protective film [31]. During hot steel rolling, the water-based nanolubricants contact the hot steel plate in an instant, and then bunch up into small liquid balls and skitter around, leading to a huge loss of NPs. However, there are still remained NPs that tumble through the steel surface and thus scrape the bumps, showing a polishing effect [32]. This may reduce the roughness of oxide scale surface with the aid of abrasion caused by NPs. At other times, the NPs are inclined to fill in the surface defects (pits and cracks) due to their small sizes [28]. This so-called mending effect contributes to the flattening of an oxide scale surface, thereby resulting in 
the decrease of surface roughness $[26,27]$. When the nano- $\mathrm{TiO}_{2}$ concentration is lower than $4.0 \mathrm{wt} \%$, the addition of NPs into water provides limited effects on reducing surface roughness of oxide scale. In contrast, a higher nano- $\mathrm{TiO}_{2}$ concentration at $8.0 \mathrm{wt} \%$ would accelerate agglomeration of NPs that plough on the oxide scale surface [33]. This may aggravates surface undulations. In another case, with the increase of rolling temperature from 850 to $950{ }^{\circ} \mathrm{C}$, the NPs are more readily lost. Therefore, less NPs act in the contact zone, and increased surface roughness is thus generated, as shown in Fig. 5.

\subsection{Formation and performance of oxides}

Steels start to oxidise when heating in the furnace and moving out of furnace to the rolling mill before hot rolling. Oxidation of iron has been extensively investigated and is well understood [34, 35]. A tertiary oxide layer consisting of wustite, magnetite and hematite forms on the iron surface above $570{ }^{\circ} \mathrm{C}$ from inner layer to the outmost [36]. The average scale thickness ratios of wustite/magnetite/hematite are approximately 95:4:1 for pure iron oxidised isothermally in the temperature range from 700 to $1100{ }^{\circ} \mathrm{C}$ [34]. Clearly, these thickness ratios do not apply for the steel without deformation shown in Fig. 9, although the order of the oxide thicknesses is in line with what has been reported for pure iron. This deviation should be attributed to the difference in oxidation behaviour between the steel and pure iron and also non-isothermal oxidation condition in this work. The oxidation of steel carried out in this work is in a varied temperature range and atmospheres, starting from heating in furnace in nitrogen, cooling during the rolling process in air, and final cooling in nitrogen (see Fig. 2). The continuous cooling will lead to the thermal stress due to the difference of thermal expansion coefficient in different oxide layers, producing pores and cracks inside the scale $[12,37]$. These cracks will slow down iron ion diffusion and reduce wustite formation but benefit for magnetite and hematite formation. Similar results were reported by many others in their steel oxidation experiments [38].

For the steel experiencing hot rolling, a significant deformation occurs on the oxide scale. As a result, substantial numbers of cracks and pores are formed, which creates lots of channels for oxygen penetration. An increased permeation of oxygen can reach the interior of inner oxides to convert wustite into magnetite, and magnetite to hematite, because of the increment of the oxygen partial pressure locally. The conversion follows the reactions below: 


$$
\begin{gathered}
6 \mathrm{FeO}+\mathrm{O}_{2}=2 \mathrm{Fe}_{3} \mathrm{O}_{4} \\
4 \mathrm{Fe}_{3} \mathrm{O}_{4}+\mathrm{O}_{2}=6 \mathrm{Fe}_{2} \mathrm{O}_{3}
\end{gathered}
$$

This explains well the increased fraction of both hematite and magnetite for steels after hot rolling as shown in Fig. 12. The conversions of wustite to magnetite and/or magnetite to hematite start from the surfaces of wustite and/or magnetite where cracks and pores are available and then go further interiors. The original wustite and magnetite may fully be converted to magnetite and hematite, respectively, or just partially converted depending on local po2. The observation of the shell-like structure with magnetite layer decorated wustite shown in Fig. 11i, is an evidence of this partial conversion.

In addition, wustite decomposes to magnetite when it is cooled to temperatures below $570{ }^{\circ} \mathrm{C}[39,40]$ according to the following eutectoid reaction:

$$
4 \mathrm{FeO}=\mathrm{Fe}_{3} \mathrm{O}_{4}+\alpha-\mathrm{Fe}
$$

The kinetics of this reaction were investigated by Hayashi et al. [41-43] in their phase transformation of thermally grown $\mathrm{FeO}$ scale on pure-Fe in air at varied temperatures. They reported that the phase transformation of $\mathrm{FeO}$ followed the following order: inward growth of the outer $\mathrm{Fe}_{3} \mathrm{O}_{4}$, proeutectoid $\mathrm{Fe}_{3} \mathrm{O}_{4}$ precipitates and $\mathrm{Fe}_{3} \mathrm{O}_{4}$ seam formation, and finally the eutectoid decomposition. Their results also revealed the requirement of a relatively longer incubation time for initiation of eutectoid decomposition. Unlike isothermal reactions used in [41-43], a continuous cooling with a fast cooling rate was applied in this work. As a result, no eutectoid laminar structure of $\mathrm{Fe}_{3} \mathrm{O}_{4}$ and $\alpha$-Fe was observed. For non-deformed steel oxidation, proeutectoid magnetite precipitates were found to be distributed inside the thick wustite layer (see Fig. 9), indicating faster kinetics of proeutectoid $\mathrm{Fe}_{3} \mathrm{O}_{4}$ formation. However, the formation of proeutectoid magnetite was not apparent in hot rolled samples. As described above, for rolled samples, most of wustite has been converted to magnetite. Therefore, amount of magnetite from decomposition of wustite is limited. Also for the rolled samples, wustite is deformed, and experiencing a rather faster cooling during hot rolling, which can suppress not only the eutectoid decomposition but also the proeutectoid precipitation.

The formation of $\mathrm{Fe}_{3} \mathrm{O}_{4}$ seam at the interface of oxide scale/substrate could also be related to the eutectoid reaction. From a thermodynamic point of view, formation of $\mathrm{Fe}_{3} \mathrm{O}_{4}$ seam at the $\mathrm{FeO} / \mathrm{Fe}$ interface lacks a 
driving force at this interface. However, the situation can be altered when Fe precipitates first. This is in fact possible as the substrate of Fe provides excellent nucleation sites for Fe nucleation and growth. As soon as $\mathrm{Fe}$ precipitates, $\mathrm{Fe}_{3} \mathrm{O}_{4}$ particulates start to precipitate at the interface of oxide scale/substrate to develop a continuous layer, forming $\mathrm{Fe}_{3} \mathrm{O}_{4}$ seam [44]. The $\mathrm{FeO} / \mathrm{Fe}$ interface is a preferential site for precipitation of $\mathrm{Fe}$ and thus can be a suitable site for a $\mathrm{Fe}_{3} \mathrm{O}_{4}$ seam formation.

As shown in Figs. 8 and 12, oxide thickness and composition of scale vary with the change of lubricant. Fig. 13 shows the rolling force as a function of the lubricant. This result reveals that the scale thickness decreases when nano- $\mathrm{TiO}_{2}$ lubricant is used. This reduction reaches the maximum when nano- $\mathrm{TiO}_{2}$ concentration is $4.0 \mathrm{wt} \%$ in lubricant, which is consistent with other reports [26, 27]. As reported previously, the $\mathrm{TiO}_{2}$ NPs in the water-based nanolubricant are able to retain on the roll surface, behaving as ball bearings under the applied rolling reduction. As a result, the abrasive friction between the roll and the steel is reduced and so is the rolling force. The lubricants with nano- $\mathrm{TiO}_{2}$ concentrations below $4.0 \mathrm{wt} \%$ have insignificant effects on reducing rolling force due to their poor wettability on work roll surfaces, and therefore insufficient $\mathrm{TiO}_{2}$ NPs enter the contact zone between the work roll and the workpiece [27]. The lubricant with a nano- $\mathrm{TiO}_{2}$ concentration higher than $4.0 \mathrm{wt} \%$ may cause severe friction in the contact zone due to the agglomeration of $\mathrm{TiO}_{2}$ NPs [28], which presents a relatively higher rolling force than that of $4.0 \mathrm{wt} \% \mathrm{TiO}_{2}$. In order to reveal the specific values of rolling force at rolling temperatures of 850 and $950{ }^{\circ} \mathrm{C}$, the force data and corresponding standard deviation are tabulated in Table 3 .

Table 3 Rolling force data and standard deviation (KN).

\begin{tabular}{|c|c|c|c|c|}
\hline $\begin{array}{l}\text { Lubrication } \\
\text { conditions }\end{array}$ & $\begin{array}{l}\text { Rolling force } \\
\text { at } 850^{\circ} \mathrm{C}\end{array}$ & $\begin{array}{l}\text { Standard } \\
\text { deviation }\end{array}$ & $\begin{array}{l}\text { Rolling force } \\
\text { at } 950^{\circ} \mathrm{C}\end{array}$ & $\begin{array}{l}\text { Standard } \\
\text { deviation }\end{array}$ \\
\hline Dry & 315.2 & 3.2 & 267.3 & 7.6 \\
\hline Water & 312.9 & 4.2 & 262.0 & 6.1 \\
\hline $1.0 \mathrm{wt} \% \mathrm{TiO}_{2}$ & 307.0 & 0.1 & 258.6 & 2.2 \\
\hline $2.0 \mathrm{wt} \% \mathrm{TiO}_{2}$ & 302.1 & 3.1 & 254.2 & 1.2 \\
\hline $4.0 \mathrm{wt} \% \mathrm{TiO}_{2}$ & 296.1 & 2.2 & 252.1 & 0.1 \\
\hline $8.0 \mathrm{wt} \% \mathrm{TiO}_{2}$ & 298.0 & 2.3 & 255.4 & 4.1 \\
\hline
\end{tabular}


The reduction of rolling force decreases the extent of oxide deformation and therefore porosity and cracks in oxide scale. Because of this, wustite conversion to magnetite should slow down and finally more wustite retains. It was also proposed that the $\mathrm{TiO}_{2}$-containing nanolubricants could form a thin protective film on the scale surface, acting as a barrier to retard oxygen diffusion and therefore to reduce steel oxidation [26, 27, 45, 46]. It is well known that wustite is the softest at the temperature range 700-1000 ${ }^{\circ} \mathrm{C}$ among the three oxide phases [8]. Therefore, wustite is more ductile and thus more resistant to wear. As a result, less fractured and denser wustite layer is observed after deformation, which should play a better effect on reducing oxygen penetration and rate of steel oxidation than other oxides with many open channels for air/oxygen access. The observation of the thinnest oxide scale in response to the lowest density of porosity and highest fraction of wustite for $4.0 \mathrm{wt} \% \mathrm{TiO}_{2}$ lubricant supports above analysis.

As revealed by quantitative phase analysis shown in Fig. 12, the dominant phase in the oxide scale is magnetite for hot rolled steels. The increase in porosity of the oxide scale accelerates both wustite conversion to magnetite and magnetite to hematite. These two reactions lead to opposite directions on the change of magnetite fraction. As a result, the final fraction of magnetite is the competitive effect of these two reactions. In addition, the decomposition of wustite should also contribute to the increase in the fraction of magnetite. Similar to wustite, magnetite is also considered to be ductile and resistant to wear, playing a positive effect in hot steel rolling [3-5].

Although the fraction of hematite also changes with the variation in lubrication and in some cases this fraction increases e.g. $4.0 \mathrm{wt} \% \mathrm{TiO}_{2}$ (Fig. 12), it does not lead to the increase in friction and rolling force, but reduces them (Fig. 13 for nano- $\mathrm{TiO}_{2}$ lubricants). This phenomenon can be explained by the dominant compositions of wustite and magnetite in the oxide scale, overwhelming the effect of hematite.

\subsection{Formation mechanism of oxide scale}

The formation mechanism of oxide scale on a steel surface under different lubrication conditions can be schematically illustrated in Fig. 14. As mentioned before, for non-deformed steels, a typical three layered structure formed with a filmy outermost $\mathrm{Fe}_{2} \mathrm{O}_{3}$ layer, a thin $\mathrm{Fe}_{3} \mathrm{O}_{4}$ interlayer, and a dominant innermost 
layer of $\mathrm{FeO}$ with island-like proeutectoid $\mathrm{Fe}_{3} \mathrm{O}_{4}$ particulates dispersed. A seam consisting of $\mathrm{Fe}_{3} \mathrm{O}_{4}$ at the interface of oxide scale/substrate, and a small number of pores in the oxide layer are also formed (Fig. 14a). For the steel after hot rolling under dry or water condition (see Fig. 14b), substantial numbers of cracks and pores are produced, leading to fast conversion of magnetite to hematite near the scale surface and magnetite to wustite close to the scale/substrate interface. However, when $\mathrm{TiO}_{2}$-containing nanolubricants are used (see Fig. 14c), $\mathrm{TiO}_{2} \mathrm{NPs}$ can reduce the abrasive friction and the rolling force due to the rolling effect. These NPs also tend to deposit on the steel substrate to form a protective film, acting as a barrier to inhibit oxygen diffusion. These effects decrease the extent of oxide deformation and therefore the porosity and cracks in oxide scale. Therefore, wustite conversion to magnetite slows down and finally more wustite retains. Last but not least, the NPs are small enough to fill in the surface defects of oxide scale, providing a mending effect to improve the surface finish.

\section{Conclusions}

Oxidation behavior of a low-alloy steel was investigated during hot rolling at 850 and $950{ }^{\circ} \mathrm{C}$ using water-based nanolubricants containing various concentrations of nano- $\mathrm{TiO}_{2}$ from 1.0 to $8.0 \mathrm{wt} \%$. For comparison purpose, the steel was also hot rolled in only water and in dry condition without any lubricant. The results indicated that the addition of $\mathrm{TiO}_{2}$ NPs in the lubricant significantly reduced the thickness of oxide scale and surface oxide roughness. This reduction reached the maximum with the $\mathrm{TiO}_{2}$ concentration of $4.0 \mathrm{wt} \%$. Raman spectroscopy revealed that for non-deformed part of steel (tapered edge of steel plate) a typical three-layered oxide scale was observed with a dominant inner layer of wustite followed by a thin magnetite and hematite layer on the top. Hot rolling, however, damaged this multi-layered structure and led to many cracks and defects inside the oxide scale. This structure accelerated oxygen access deeply into the oxide scale interior and promoted the conversion of wustite to magnetite in the inner area and magnetite to hematite in the outer zone. As a result, more magnetite and hematite were formed as demonstrated by oxide component fraction determination. The presence of $\mathrm{TiO}_{2}$ NPs was found to decrease the rolling force and therefore less deformation to the oxide scale. Because of this, a higher fraction of wustite was retained. The relatively dense structure retarded the oxygen access to oxide interior and reduced the rate of steel oxidation. Increasing temperature did not affect the trend of 
lubrication effect but increased the total rate of steel oxidation.

\section{Acknowledgements}

The authors acknowledge the financial supports from Baosteel-Australia Joint Research \& Development Center (BAJC) under the project of BA17004 and Australian Research Council (ARC) under Linkage Project Program (LP150100591). The authors are grateful to Mr. Suoquan Zhang at Baosteel Research Institute for the provision of steel samples. We would like to thank the technicians in the workshop of SMART Infrastructure Facility at University of Wollongong for their kind help on samples machining. We also wish to extend special thanks to A/Prof. Buyung Kosasih and Mr. Long Wang for their great supports on the ultrasonic treatment of applied lubricants. Thanks also go to Drs. Lin Wang and Chun Yu who participated in some oxide analyses when they were working at UNSW.

\section{References}

1. L. Suárez, Y. Houbaert, X. V. Eynde, and R. Colás, Corrosion Science 51, 2009 (309).

2. X. Cheng, Z. Jiang, D. Wei, L. Hao, J. Zhao, and L. Jiang, Tribology International 84, 2015 (61).

3. T. Jia, Z. Y. Liu, H. F. Hu, and G. D. Wang, ISIJ International 51, 2011 (1468).

4. X. Yu, Z. Jiang, J. Zhao, D. Wei, C. Zhou, and Q. Huang, Corrosion Science 90, 2015 (140).

5. X. Yu, Z. Jiang, J. Zhao, D. Wei, C. Zhou, and Q. Huang, Wear 332-333, 2015 (1286).

6. Z. Y. Jiang, J. Tang, W. Sun, A. K. Tieu, and D. Wei, Tribology International 43, 2010 (1339).

7. X. Cheng, Z. Jiang, J. Zhao, D. Wei, L. Hao, J. Peng, M. Luo, L. Ma, S. Luo, and L. Jiang, Wear 338-339, 2015 (178).

8. P. A. Munther and J. G. Lenard, Journal of Materials Processing Technology 88, 1999 (105).

9. L. Luong and T. Heijkoop, Wear 71, 1981 (93).

10. H. Utsunomiya, T. Nakagawa, and R. Matsumoto, Procedia Manufacturing 15, 2018 (46).

11. R. Y. Chen and W. Y. D. Yuen, Oxidation of Metals 56, 2001 (89).

12. S. Birosca, D. Dingley, and R. L. Higginson, Journal of Microscopy 213, 2004 (235).

13. S. Garber and G. Sturgeon, 1959

14. H. Wriedt, Binary alloy phase diagrams, second edition, ed. Massalski B 2, 1990

15. X. Yu, Z. Jiang, J. Zhao, D. Wei, C. Zhou, and Q. Huang, Corrosion Science 85, 2014 (115).

16. X. L. Yu, Z. Y. Jiang, J. W. Zhao, D. B. Wei, and C. L. Zhou, Applied Mechanics and Materials 395-396, 2013 (273).

17. D. B. Lee and J. W. Choi, Oxidation of Metals 64, 2005 (319).

18. F. H. Stott, G. C. Wood, and J. Stringer, Oxidation of Metals 44, 1995 (113).

19. K. Dohda, C. Boher, F. Rezai-Aria, and N. Mahayotsanun, Friction 3, 2015 (1).

20. H. Wu, F. Jia, J. Zhao, S. Huang, L. Wang, S. Jiao, H. Huang, and Z. Jiang, Wear 426-427, 2019 (792).

21. H. Xie, S. Dang, B. Jiang, L. Xiang, S. Zhou, H. Sheng, T. Yang, and F. Pan, Applied Surface Science 475, 2019 (847). 
22. S. Du, J. Sun, and P. Wu, Carbon 140, 2018 (338).

23. A. S. He, S. Q. Huang, J. H. Yun, H. Wu, Z. Y. Jiang, J. Stokes, S. H. Jiao, L. Z. Wang, and H. Huang, Tribology Letters 65, 2017 (40).

24. Y. Bao, J. Sun, and L. Kong, Tribology International 114, 2017 (257).

25. Y. Meng, J. Sun, P. Wu, C. Dong, and X. Yan, Nanomaterials 8, 2018 (111).

26. H. Wu, J. Zhao, L. Luo, S. Huang, L. Wang, S. Zhang, S. Jiao, H. Huang, and Z. Jiang, Lubricants 6, 2018 (57).

27. H. Wu, J. Zhao, W. Xia, X. Cheng, A. He, J. H. Yun, L. Wang, H. Huang, S. Jiao, L. Huang, S. Zhang, and Z. Jiang, Journal of Manufacturing Processes 27, 2017 (26).

28. H. Wu, J. Zhao, W. Xia, X. Cheng, A. He, J. H. Yun, L. Wang, H. Huang, S. Jiao, L. Huang, S. Zhang, and Z. Jiang, Tribology International 109, 2017 (398).

29. H. Wu, J. Zhao, X. Cheng, W. Xia, A. He, J.-H. Yun, S. Huang, L. Wang, H. Huang, S. Jiao, and Z. Jiang, Tribology International 117, 2018 (24).

30. B. G. R K Singh Raman, D J Young, Mater. Sci. Technol. 14, 1998 (373).

31. K. Lee, Y. Hwang, S. Cheong, Y. Choi, L. Kwon, J. Lee, and S. H. Kim, Tribology Letters 35, 2009 (127).

32. X. Tao, Z. Jiazheng, and X. Kang, Journal of Physics D: Applied Physics 29, 1996 (2932).

33. R. Dwyer-Joyce, R. Sayles, and E. Ioannides, Wear 175, 1994 (133).

34. S. Mrowec and K. Przybylski, Oxid. Met. 11, 1977 (383).

35. M. H. Davies, M. T. Simnad, and C. E. Birchenall, Jom 3, 1951 (889).

36. R. Y. Chen and W. Y. D. Yeun, Oxidation of Metals 59, 2003 (433).

37. D. P. Burke and R. L. Higginson, Scripta Materialia 42, 2000 (277).

38. Z.-f. Li, G.-m. Cao, F. Lin, H. Wang, and Z.-y. Liu, Oxid. Met. 90, 2018 (337).

39. J. Tominaga, K.-y. Wakimoto, T. Mori, M. Murakami, and T. Yoshimura, Trans. ISIJ. 22, 1982 (646).

40. W. Sun, A. K. Tieu, Z. Jiang, H. Zhu, and C. Lu, J. Mater. Proces. Technol. 155-156, 2004 (1300).

41. S. Hayashi, K. Mizumoto, S. Yoneda, Y. Kondo, H. Tanei, and S. Ukai, Oxidation of Metals 81, 2014 (357).

42. Y. Shizukawa, S. Hayashi, S. Yoneda, Y. Kondo, H. Tanei, and S. Ukai, Oxidation of Metals 86, 2016 (315).

43. S. Yoneda, S. Hayashi, Y. Kondo, H. Tanei, and S. Ukai, Oxidation of Metals 87, 2017 (125).

44. X. Yu, Z. Jiang, D. Wei, C. Zhou, Q. Huang, and D. Yang, Wear 302, 2013 (1286).

45. K. Mori and D. Ito, CIRP Annals 58, 2009 (267).

46. P. Liu, L. Wei, S. Ye, H. Xu, and Y. Chen, Surface and Coatings Technology 205, 2011 (3582). 


\section{Figures}

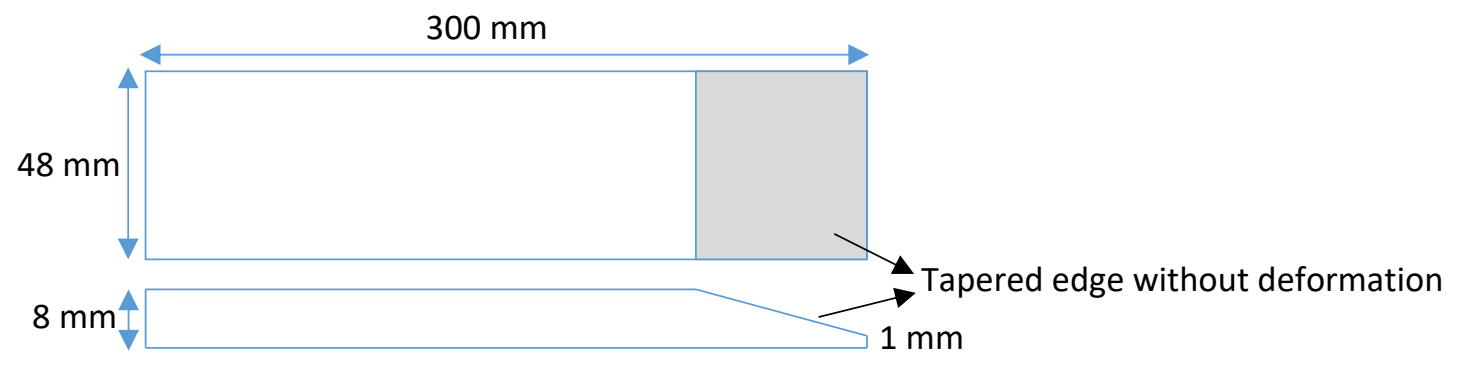

Fig. 1 Schematic view of steel plate used for hot rolling.

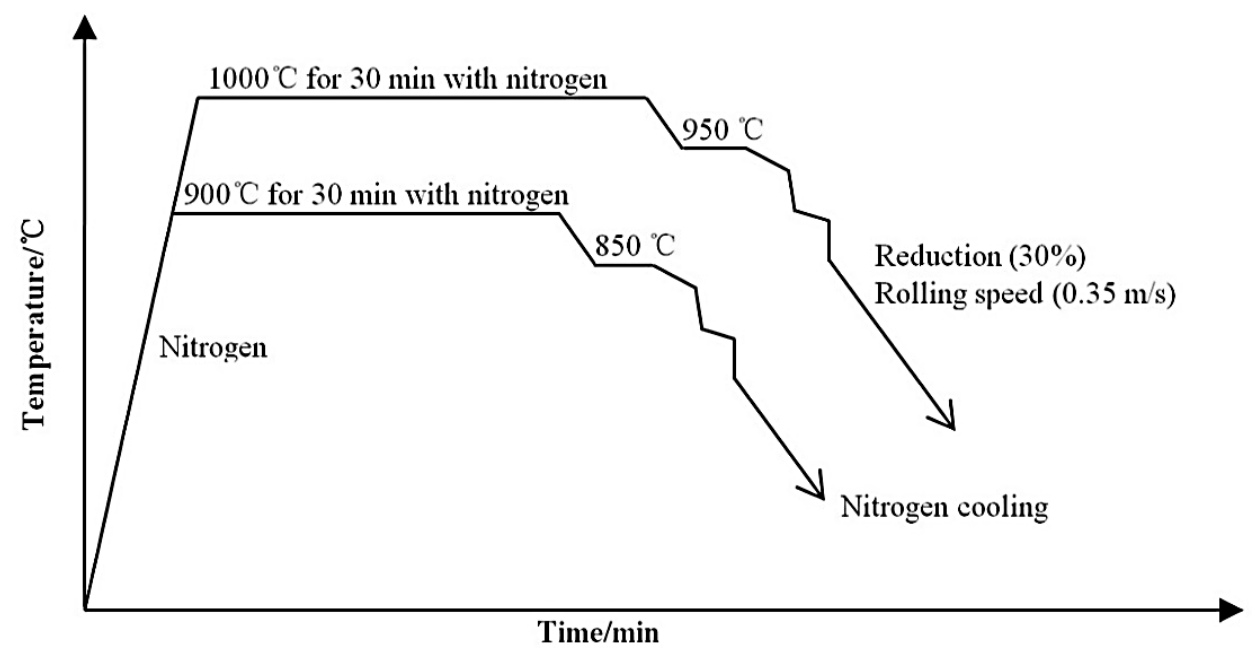

Fig. 2 The procedure of hot rolling testing. 

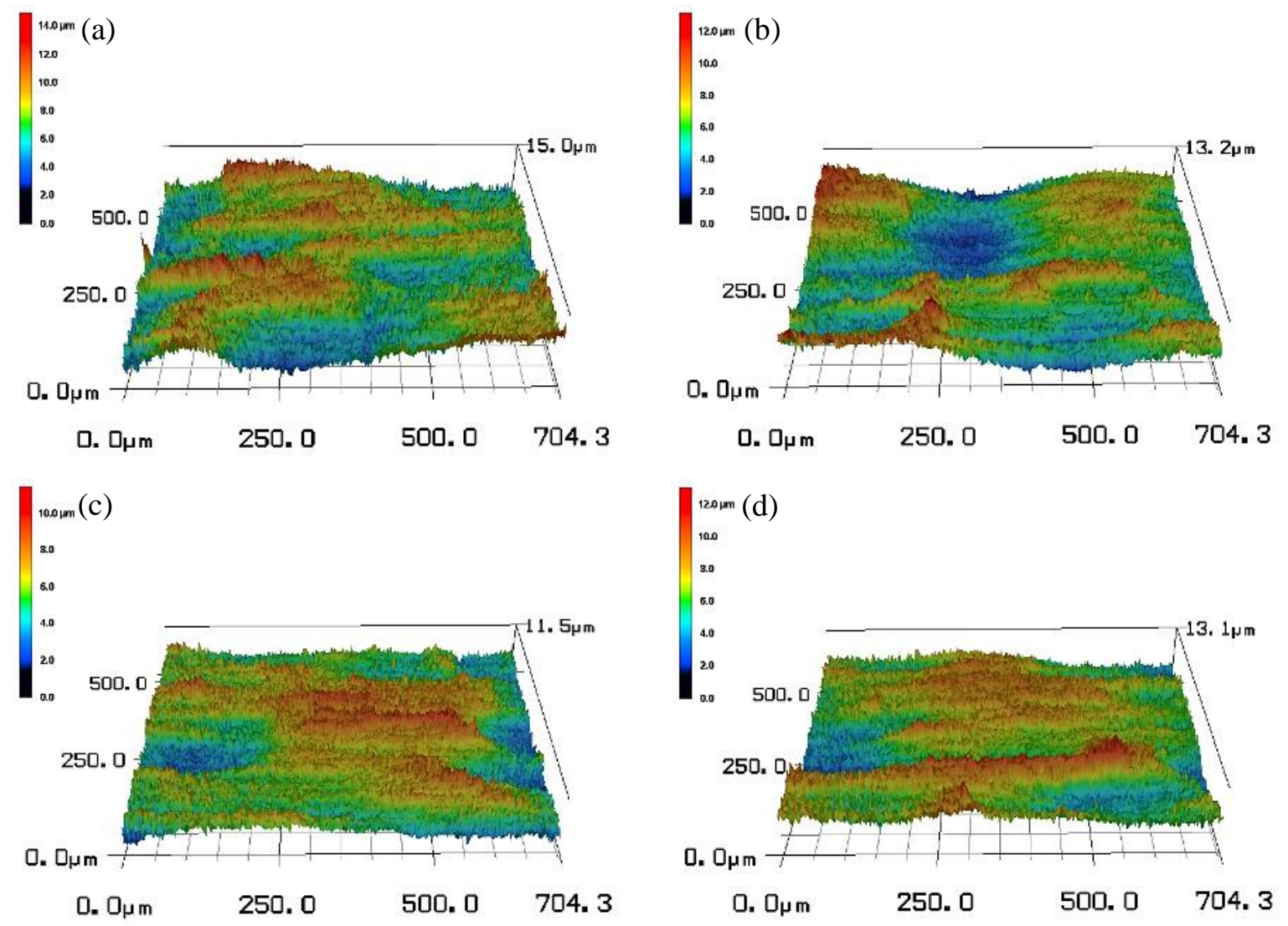

Fig. 3 3D surface topographies of the oxide scales produced at $850{ }^{\circ} \mathrm{C}$ under different lubrication conditions of (a) dry, (b) $1.0 \mathrm{wt} \% \mathrm{TiO}_{2}$, (c) $4.0 \mathrm{wt} \% \mathrm{TiO}_{2}$, and (d) $8.0 \mathrm{wt} \% \mathrm{TiO}_{2}$. 

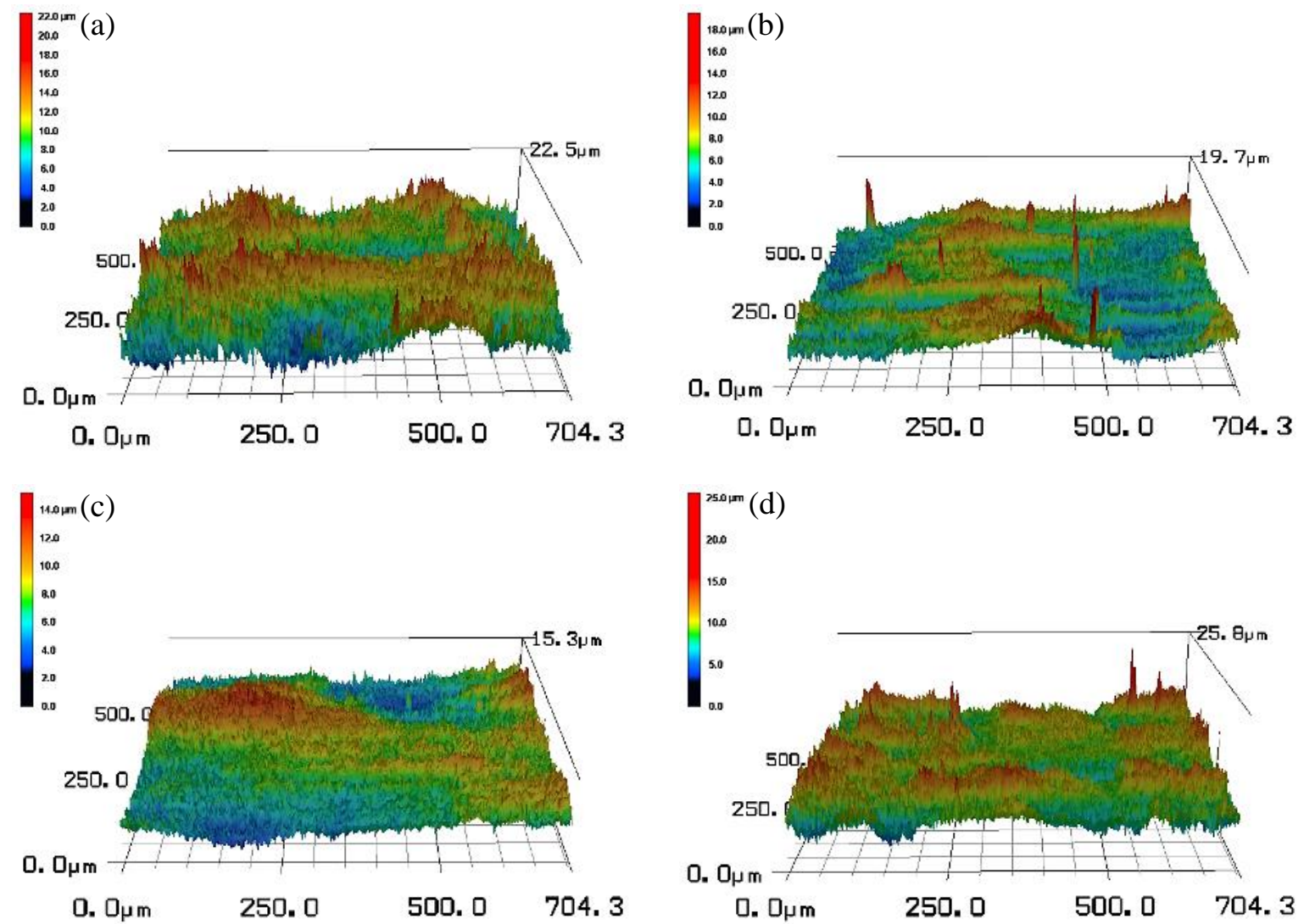

Fig. 4 3D surface topographies of the oxide scales produced at $950{ }^{\circ} \mathrm{C}$ under different lubrication conditions of (a) dry, (b) $1.0 \mathrm{wt} \% \mathrm{TiO}_{2}$, (c) $4.0 \mathrm{wt} \% \mathrm{TiO}_{2}$, and (d) $8.0 \mathrm{wt} \% \mathrm{TiO}_{2}$. 


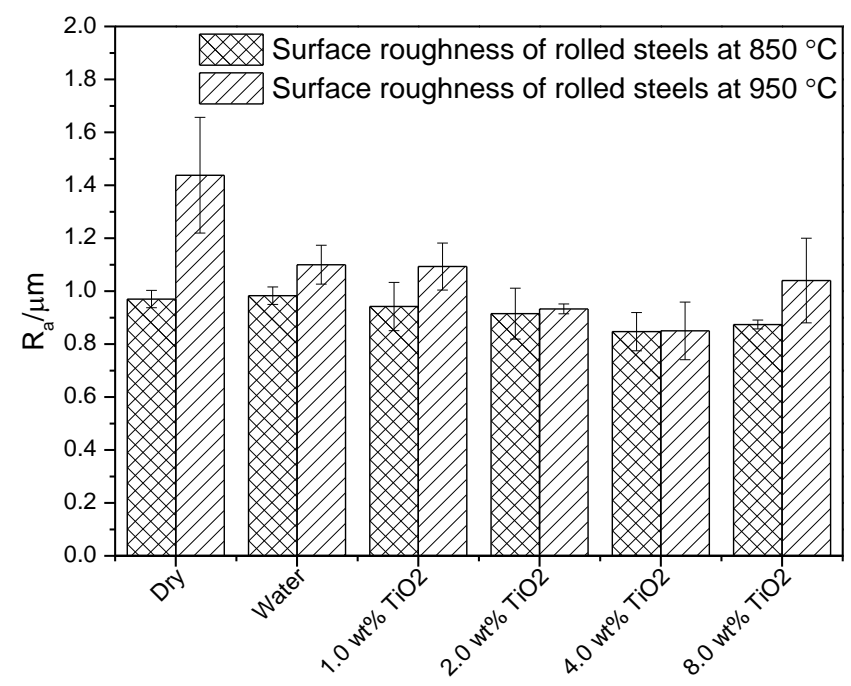

Fig. 5 Surface roughness of the oxide scales obtained at 850 and $950{ }^{\circ} \mathrm{C}$ under different lubrication conditions. 


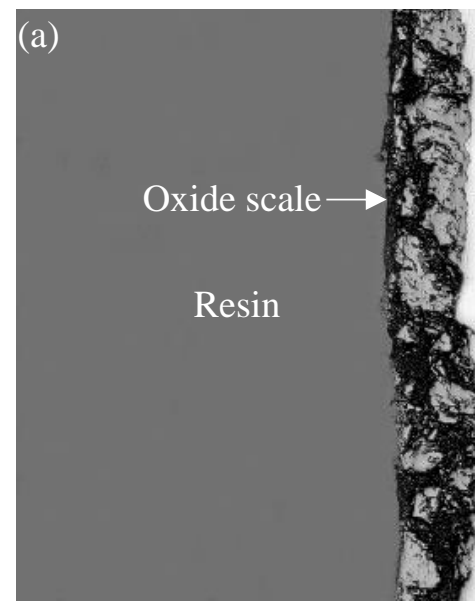

(c)

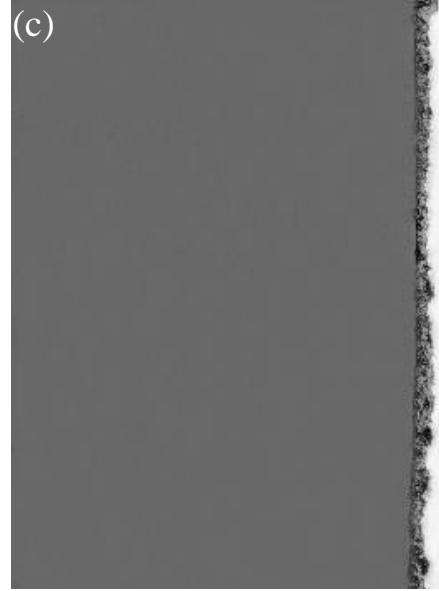

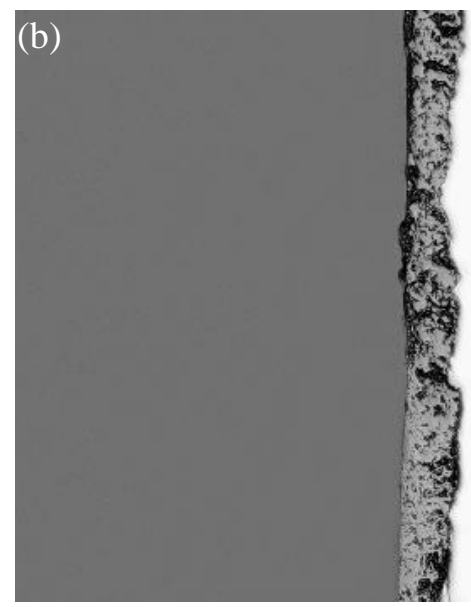

$\stackrel{50 \mu \mathrm{m}}{\longmapsto}$

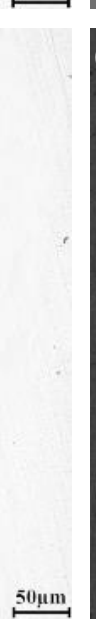

(d)

$50 \mu \mathrm{m}$

Fig. 6 Optical images of the cross-section of oxide scales formed at $850{ }^{\circ} \mathrm{C}$ under different lubrication conditions of (a) dry, (b) $1.0 \mathrm{wt} \% \mathrm{TiO}_{2}$, (c) $4.0 \mathrm{wt} \% \mathrm{TiO}_{2}$, and (d) $8.0 \mathrm{wt} \% \mathrm{TiO}_{2}$. 

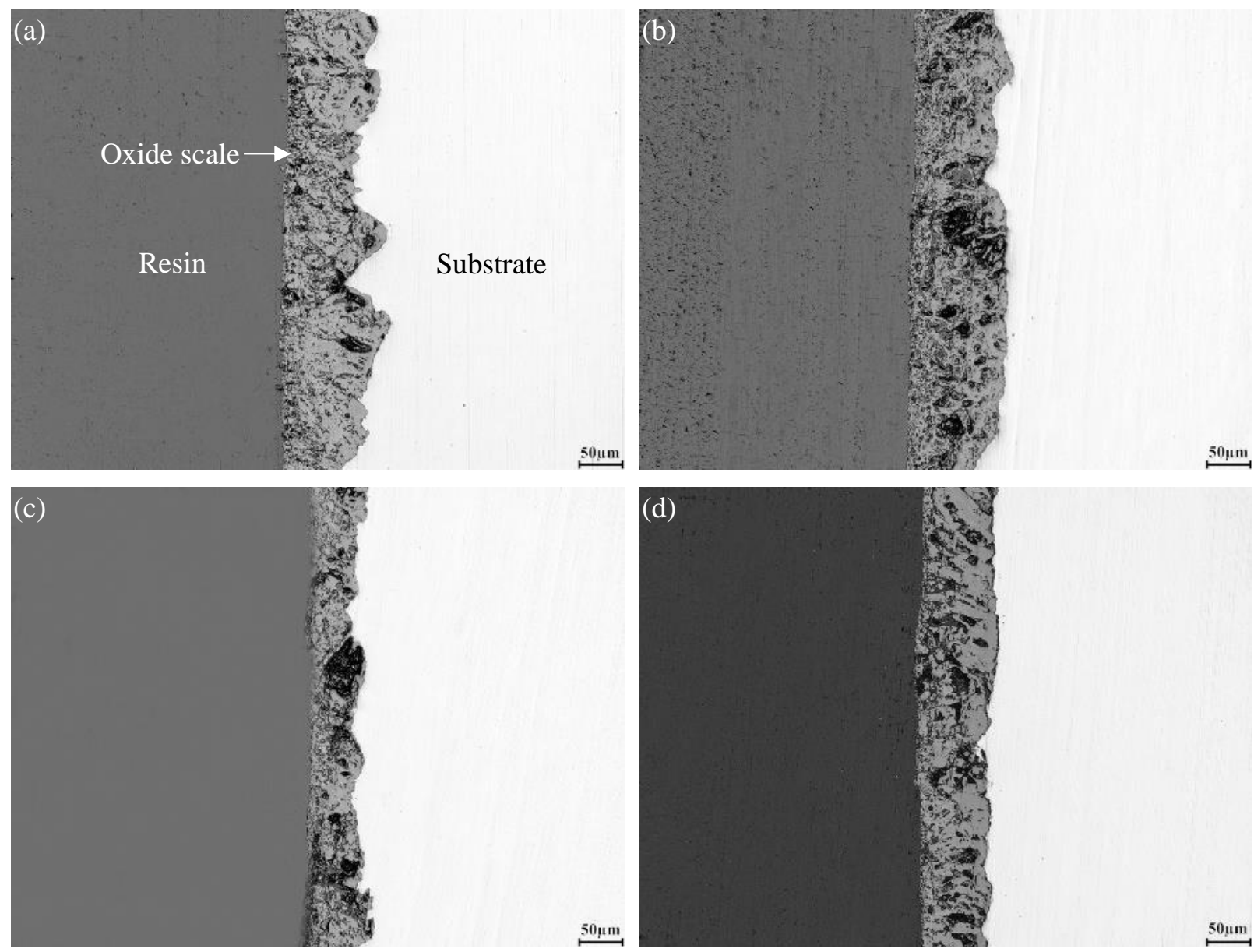

Fig. 7 Optical images of the cross-section of oxide scales formed at $950{ }^{\circ} \mathrm{C}$ under different lubrication conditions of (a) dry, (b) $1.0 \mathrm{wt} \% \mathrm{TiO}_{2}$, (c) $4.0 \mathrm{wt} \% \mathrm{TiO}_{2}$, and (d) $8.0 \mathrm{wt} \% \mathrm{TiO}_{2}$. 


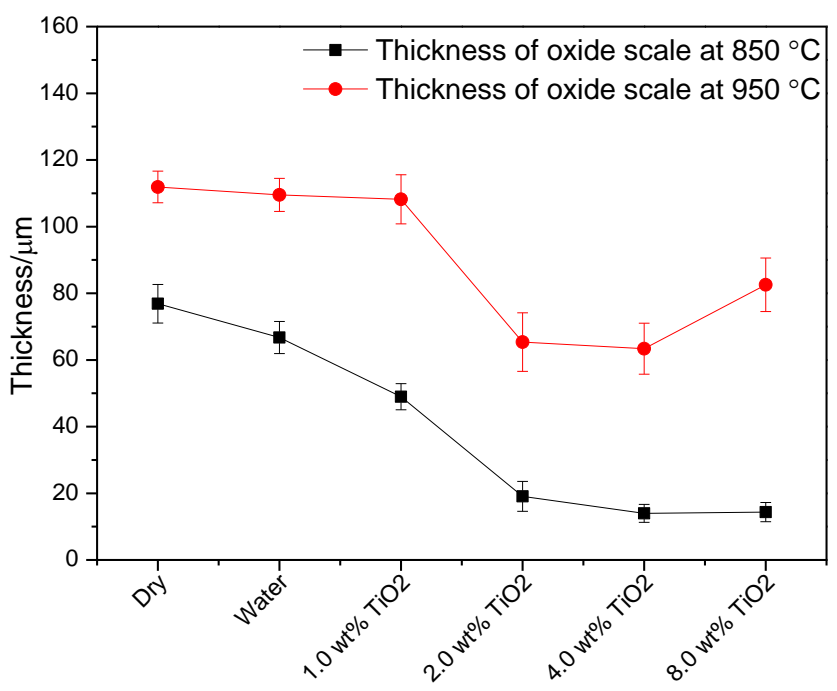

Fig. 8 Thickness of oxide scale formed at 850 and $950{ }^{\circ} \mathrm{C}$ under different lubrication conditions. 

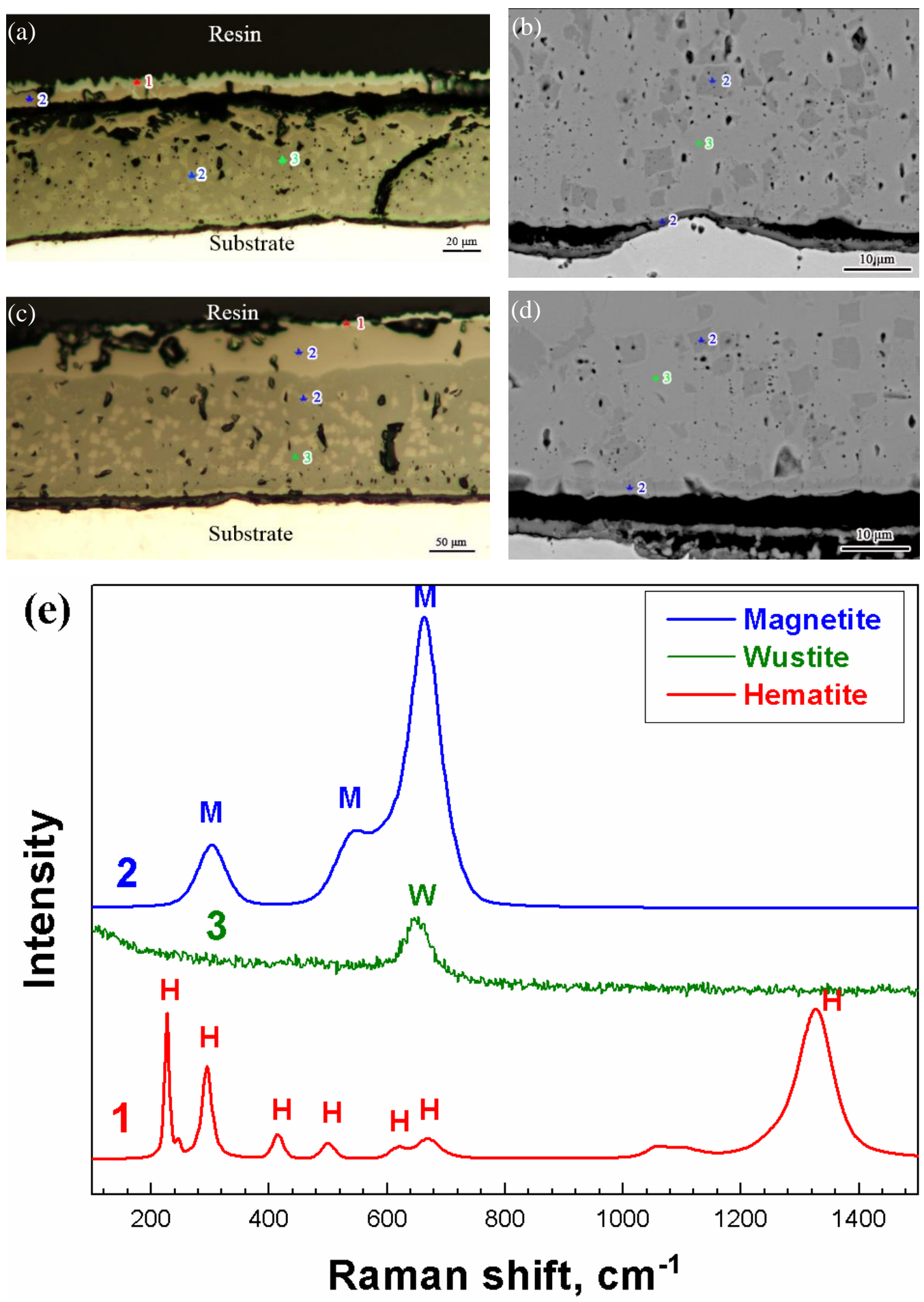

Fig. 9 Optical and BSE-SEM cross-section images of steels without deformation at $850{ }^{\circ} \mathrm{C}$ ((a) optical, (b) BSE) and $950{ }^{\circ} \mathrm{C}$ ((c) optical, (d) BSE), and (e) Raman spectra of points in oxide scale. 

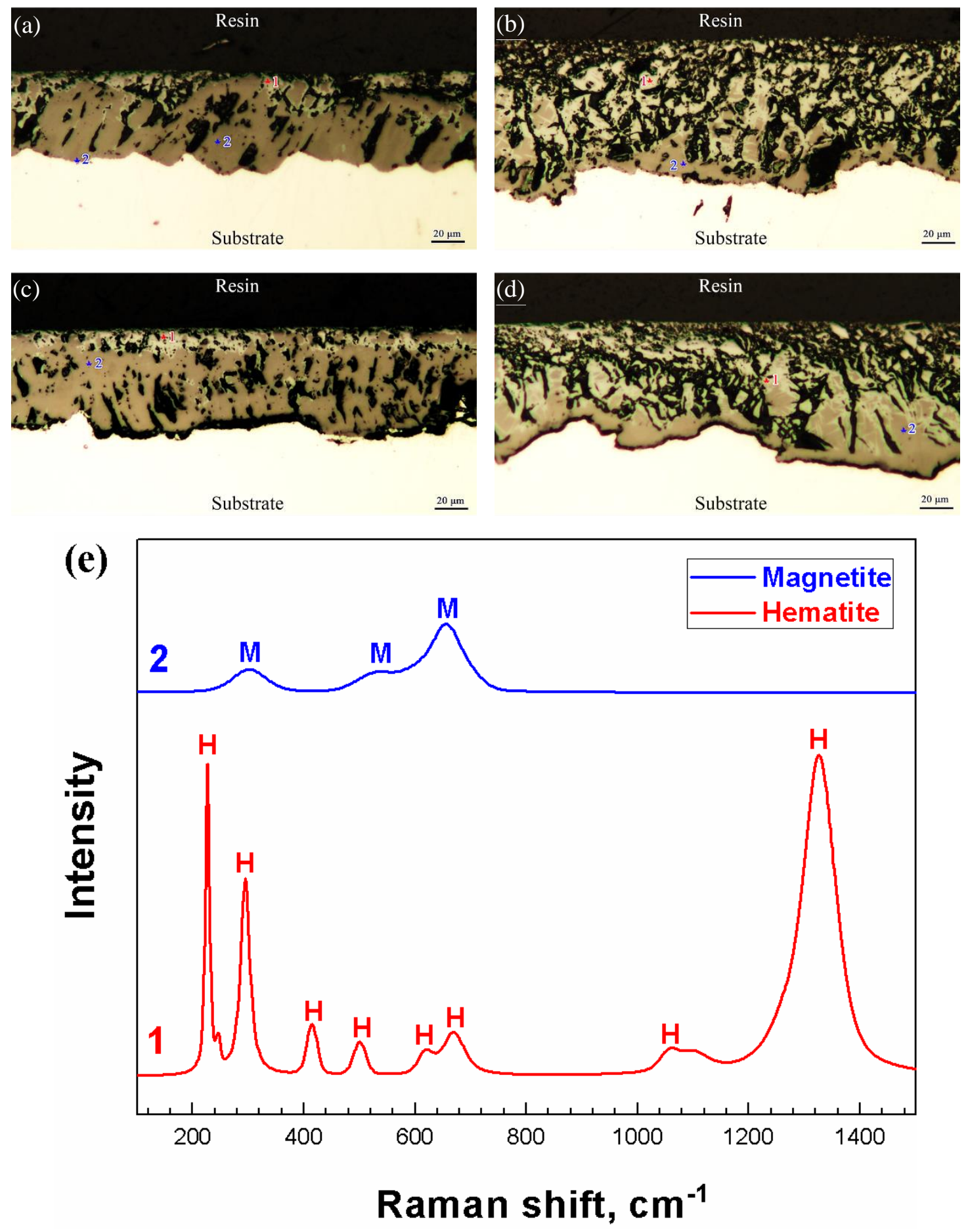

Fig. 10 Optical cross-section images of steels under dry and water conditions at $850{ }^{\circ} \mathrm{C}$ ((a) dry, (c) water) and $950{ }^{\circ} \mathrm{C}$ ((b) dry, (d) water), and (e) Raman spectra of points in oxide scale. 

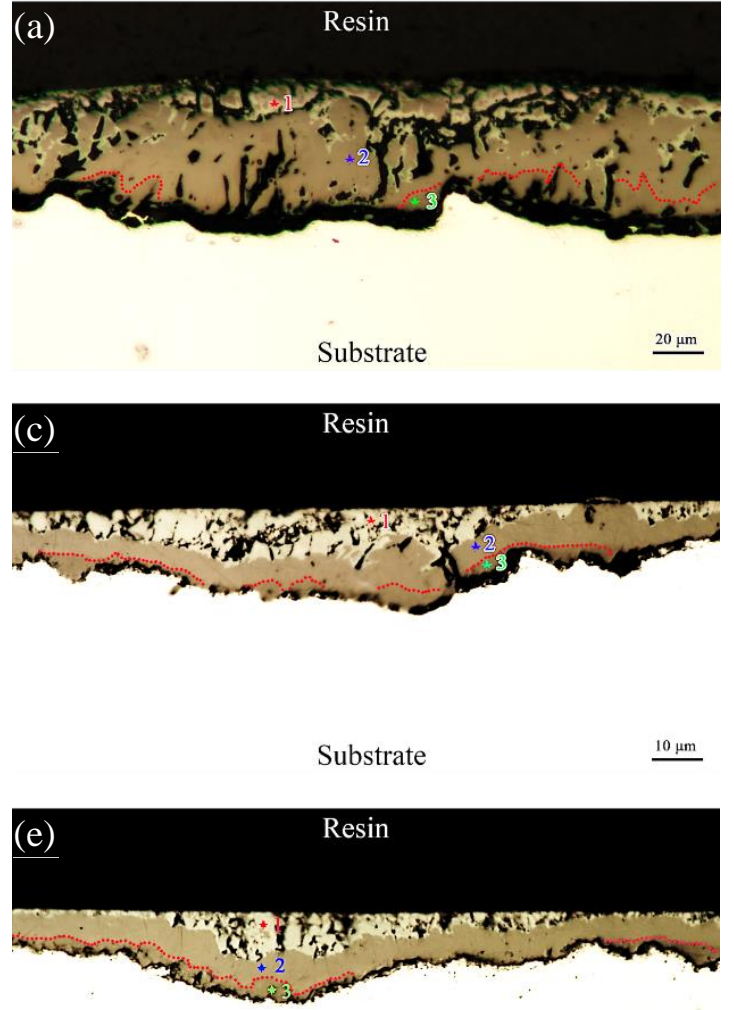

Substrate

$10 \mu \mathrm{mm}$

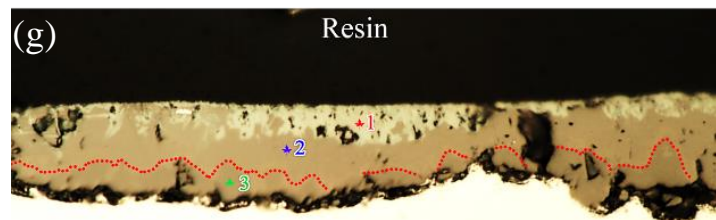

Substrate

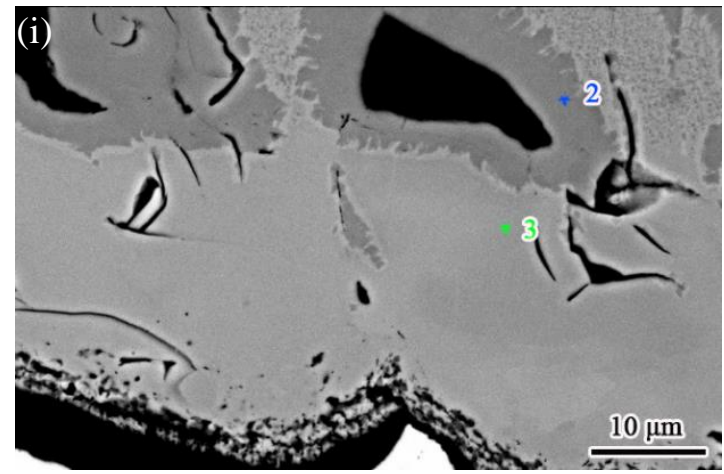

$10 \mu \mathrm{m}$
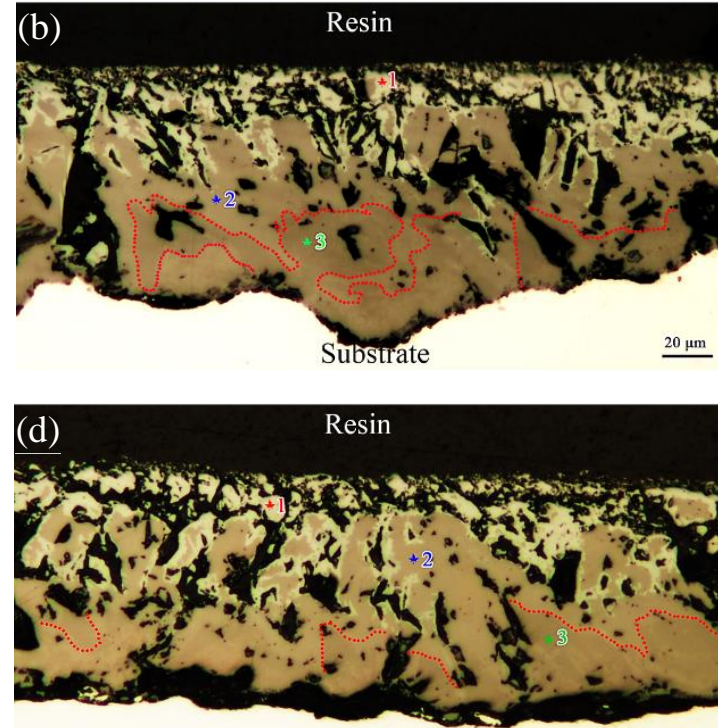

Substrate

$20 \mu \mathrm{m}$

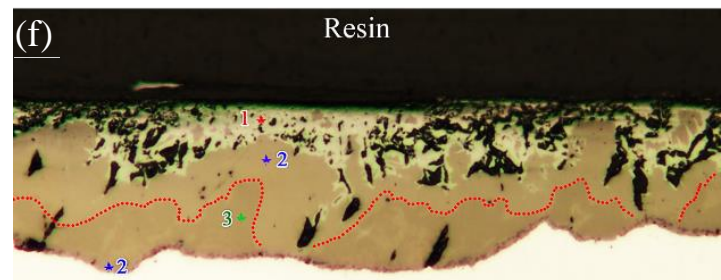

Substrate

$20 \mu \mathrm{m}$
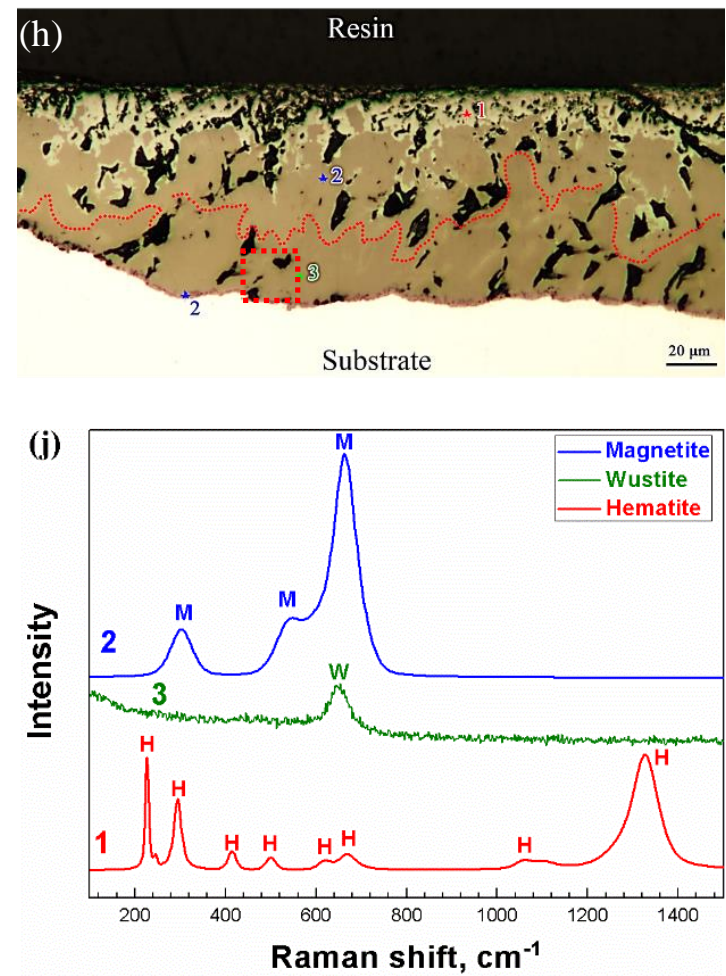
Fig. 11 Optical cross-section images of steels under various nano- $\mathrm{TiO}_{2}$ particle lubrication conditions at $850{ }^{\circ} \mathrm{C} \mathrm{((a)} 1.0 \mathrm{wt} \% \mathrm{TiO}_{2}$, (c) $2.0 \mathrm{wt} \% \mathrm{TiO}_{2}$, (e) $4.0 \mathrm{wt} \% \mathrm{TiO}_{2}$ and $(\mathrm{g}) 8.0 \mathrm{wt} \% \mathrm{TiO}_{2}$ ) and $950{ }^{\circ} \mathrm{C}$ ((b) 1.0 $\mathrm{wt} \% \mathrm{TiO}_{2}$, (d) $2.0 \mathrm{wt} \% \mathrm{TiO}_{2}$, (f) $4.0 \mathrm{wt} \% \mathrm{TiO}_{2}$ and (h) $8.0 \mathrm{wt} \% \mathrm{TiO}_{2}$ ), (i) BSE-SEM cross-section image of shell-like structure for red rectangle in Fig. 12h, and (j) Raman spectra of points in oxide scale.
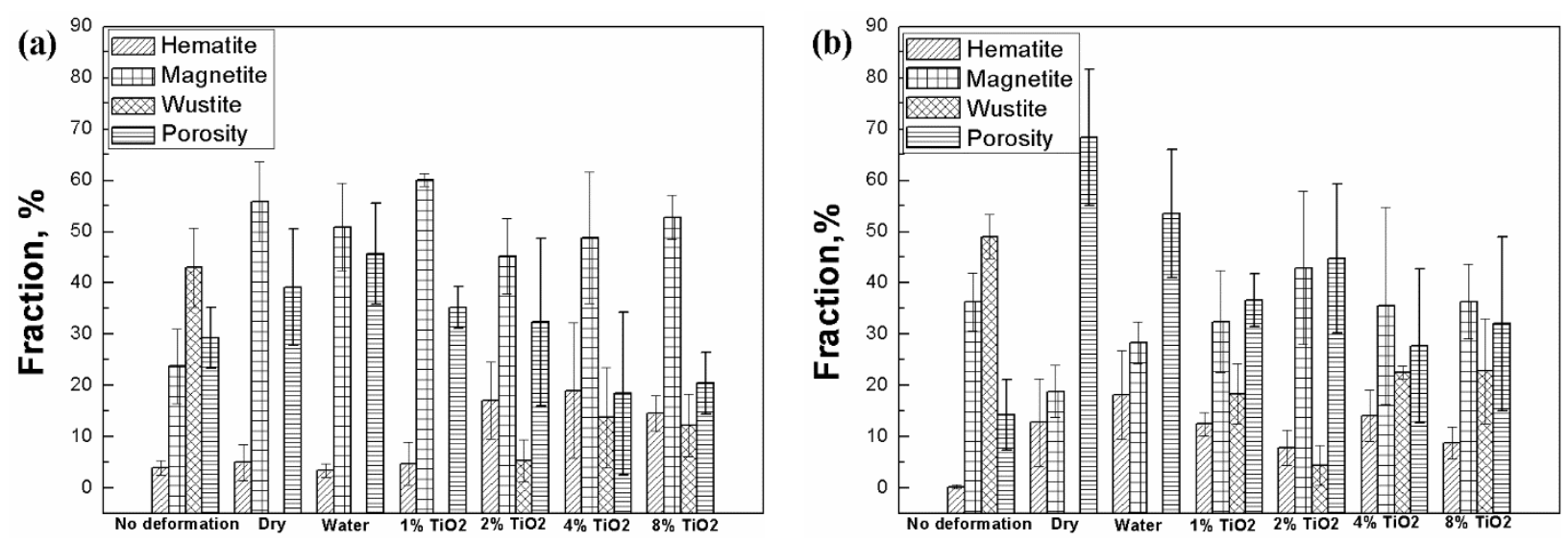

Fig. 12 The fractions of different oxide phases and porosity under various lubrication conditions at (a) $850{ }^{\circ} \mathrm{C}$, and (b) $950{ }^{\circ} \mathrm{C}$.

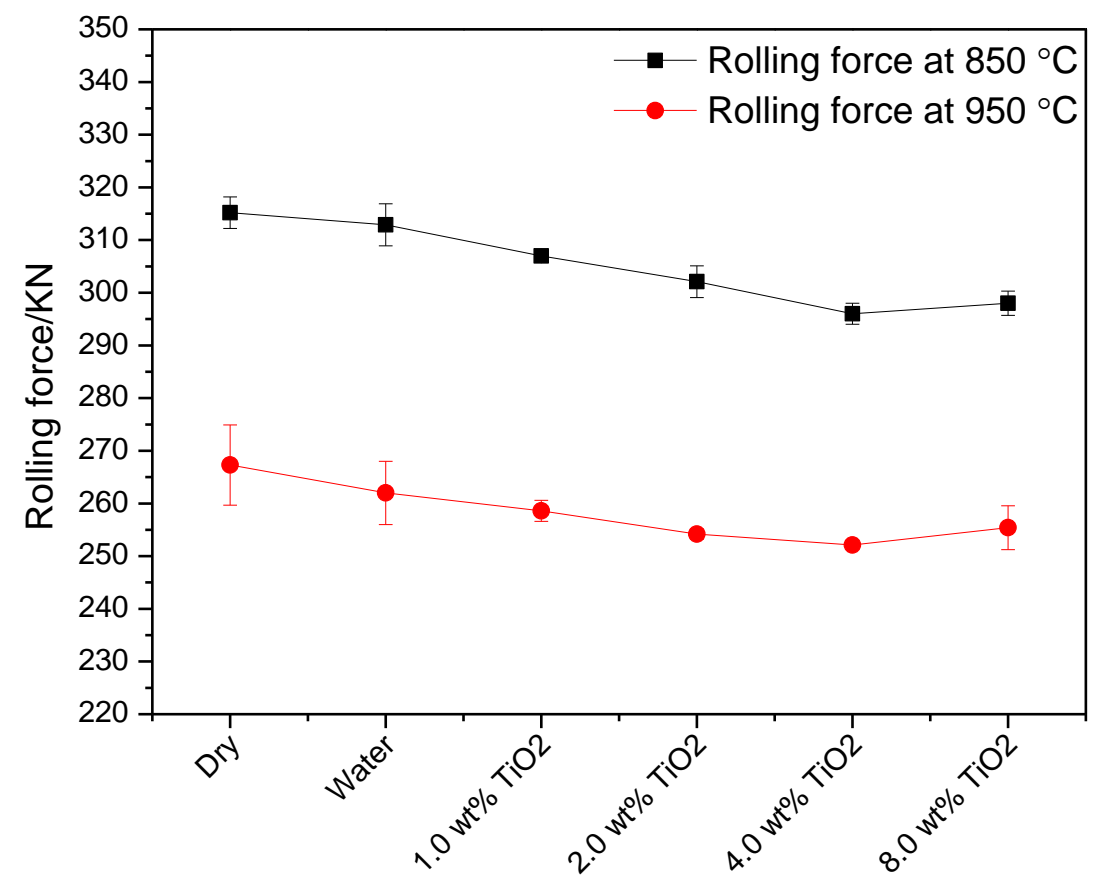

Fig. 13 Rolling force obtained under different lubrication conditions at rolling temperatures of 850 and $950{ }^{\circ} \mathrm{C}$. 

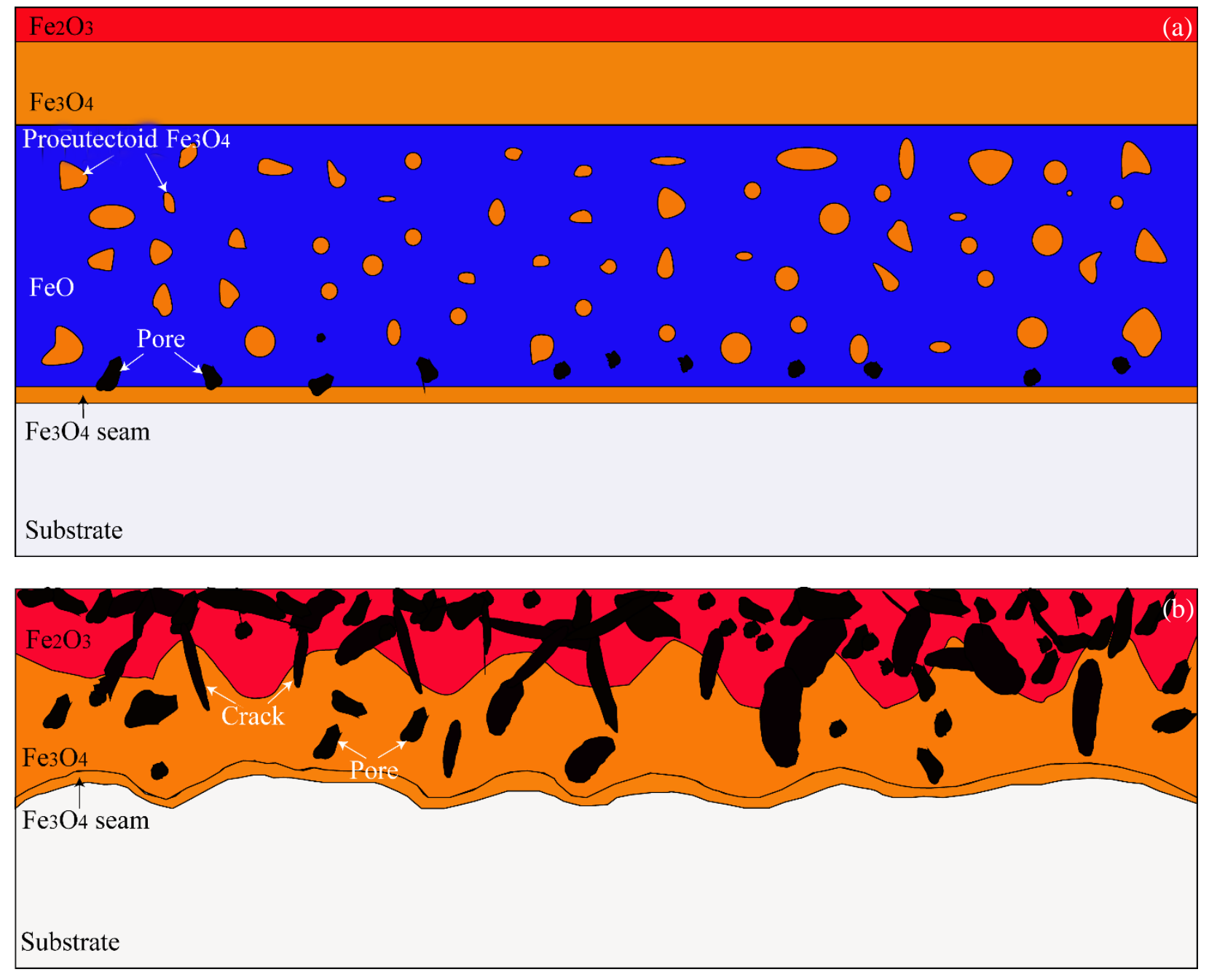

\section{TiO2 Protective film}

Rolling effect Mending effect Substrate

Fig. 14 Schematic illustration of oxide scale formed on steel surface under (a) no deformation, (b) dry or water condition, and (c) $\mathrm{TiO}_{2}$-containing nanolubrication conditions. 